\title{
The Role of Business and Information Systems Engineering in E-Government
}

\author{
DOI 10.1007/s12599-011-0182-4
}

\section{The Authors}

Prof. Dr. Hans Ulrich Buhl ( $₫)$

FIM Research Center Finance \& Information Management University of Augsburg

Universitätsstraße 12

86159 Augsburg

Germany

hans-ulrich.buhl@

wiwi.uni-augsburg.de

Dr. Markus Löffler

McKinsey \& Company, Inc.

Birkenwaldstraße 149

70191 Stuttgart

Germany

markus_loeffler@mckinsey.com

Published online: 2011-10-12

This article is also available in German in print and via http://www. wirtschaftsinformatik.de: Buhl $\mathrm{HU}$, Löffler M (2011) Die Rolle der Wirtschaftsinformatik im E-Government. WIRTSCHAFTSINFORMATIK. doi: 10. 1007/s11576-011-0293-Z.

(C) Gabler Verlag 2011
"In memoriam Elena". This was the headline of an article published in an important German weekly newspaper at the end of July this year. One can easily imagine this entithes the expected end of the governmental program for digital collection of employees' data in Germany. This struggle to achieve an efficient governmental administration has now failed once and for all, which unfortunately is no global exception but represents numerous "well thought and badly realized" IT-projects of this kind within the public sector.

But why are such mammoth projects initiated in the public sector and which role does IT play here? International debt crisis, financial crisis, or economic crisis, the demographic change, new technologies as well as increased safety demands are just some of the challenges the administrative organization of multiple countries need to take up. Additionally, the citizens' level of expectation for higher performance and better service is increasing whereas - due to the pressure of rising costs - the governmental processes have to cope with the task of becoming more and more "efficient".

In this mesh of requirements, developments, and interest groups the idea of E-Government can be regarded as a practical attempt at a solution. The objective and vision behind IT-projects in E-Government contexts are clear and understandable: simplification and realization of information, communication, and transaction processes within and between governmental, local, and other official institutions as well as between these institutions and citizens and companies respectively by using digital information and communication technology.

Here, IT can be seen as an enabler for a modern administration. Exemplarily, automation, streamlining, and harmonization of common governmental processes by means of building and developing shared service centers as well as the development and supply of portals can open potential for rationalization and finally ease the public budget. Although the underlying motivation is unambiguous and research as well as practice demonstrate lively interest in this objective - as many conferences (e.g., European Conference on E-Government, International Conference on E-Government) and journals (e.g., Electronic Journal of E-Government) in the context of E-Government indicate - realization is often a difficult, time-consuming, and scarcely accepted undertaking.

What are the reasons that such projects in the administration - which is the sector with the highest IT-demand with expenditures of over $\$ 490$ billion per anno worldwide (Gartner 2010) - do not receive public acceptance, although the objectives of cost reduction and more service for citizens are targeted? Why do E-Government efforts have to be postponed or even suspended in spite of immense investments?

The answer to these questions requires a differentiated consideration. Exemplarily, a study conducted in 2010 shows (IDG NOA Sonderstudie 2010) that the public takes an extremely skeptical view on E-Government efforts. In particular, concerns about data protection and data security - especially the lacking transfer security and the conscientiousness when dealing with data - are described as critical aspects. First of all, the public is afraid to become "transparent citizens" and therefore takes a defensive position. Besides incidents in private enterprises - the hacker attack on the "playstation"network of Sony in spring 2011 caused an economic damage estimated at more than $\$ 170$ million - of course other incidents within the governmental administration result in stirring up more (partly justified) misgivings. For example, in Estonia a "denial of service" attack in 2007 briefly paralyzed a majority of the IT-infrastructure of banks, authorities, the police, and the government, which naturally reduced the public trust in E-Government endeavors.

Apart from such external attacks, also already failed projects or projects with a catastrophic cost-benefit-ratio increase the public concerns. Unfortunately, the above mentioned example Elena is no exception. 
Moreover, the program "virtual case file" of the Federal Bureau of Investigation (better known as FBI) can be named as a prominent example. After the attacks of 09-11 the US-commission demanded an urgent renewal of the outdated IT-systems of the FBI in order to support the inquiries concerning the terrorist attack. Via the "virtual case file" program, it was the FBI's intention to modernize its whole system for administration and distribution of information. After almost four years, when already \$170 million were spent, the project was finally stopped. Lacking program management knowledge as well as high fluctuation within IT-managers are listed as reasons for the failure.

The electronic health card ("elektronische Gesundheitskarte") is another example from Germany. Although the first issue of the electronic health card was planned for the 1st of January 2006, the German insurants are still expecting the overall introduction to this day. The aim of this project is to create more modern and more economic processes in the public health system by means of telematics in order to avoid repeated examinations and multiple registrations of identical data (Mertens 2008). Naturally, owing to the sensitivity of citizens' health information, data protection is of great importance and has called the critical voices of doctors, citizens, and data protectionists into action. Besides high costs for the project due to the central data storage, they also are afraid of the possibility of unauthorized access to sensitive data of patients as well as the hazard of improper use and fake.

A final example from Britain shows how even finally successful major projects stand on the brink of failure, driven by specific conditions of the public sector. At the end of the 1990s the British Passport Service (UKPS) intended to introduce a new forgeryproof passport. Due to the out-dated systems of the UKPS, essential subtasks (processing applications after examination through the UKPS, call center operations, supply of the IT-platform) were assigned to the former Siemens Business Services within the context of a business process outsourcing project. The new processes were introduced in 1998, but did not nearly reach the necessary efficiency: in June 1999 - at the beginning of holidays - the backflow of unprocessed applications for passports amounted to 565.000. Only cost-intensive emergency measures on both sides - UKPS and Siemens Business Services - could stabilize this situation. By the end of 2001, finally the complete rollout took place and received a proven customer satisfaction rate of $99.9 \%$.

What where the reasons for this massive project crisis? Besides problems IT-projects have to cope with also in private enterprises (too ambitioned schedules for market entry, technical complications), there were challenges, which are typical for public projects: requirements changed dramatically in the course of time due to the altering general set-ups (necessity of issuing a passport also for newborns), and the public reacted differently than expected ("run" on the new passports in order not to find yourself without identity card shortly before a journey).

These examples illustrate typical reasons for the failure of IT-projects in the public sector:

- Governments face a complex environment, where conditions and requirements are in parts totally different compared to private enterprises. Numerous interest groups need to be satisfied and the project progress is critically followed by the population and the respective opposition. After all it is the taxpayers' money that is used for the realization of these projects. The project results need to be considerably more transparent since they are under critical observation of the press and the public interest.

- The general conditions for and objectives of projects are often subject to dynamic changes. New political emphasis and legislation need to be integrated into running projects. Thus, E-Government endeavors often face legal obstacles which partly owe to lacking IT-knowledge or even to apprehensions of following a wrong direction. Also the orientation of a - possibly changing - government or ruling party as well as the impact of the opposition are huge challenges for such mostly long-term projects.

- Initial budget planning and scheduling are typically and deliberately defined in an optimistic and over-ambitioned manner. There is a tendency to take into account cost or time overruns during the project, rather than to start with a high budget strategy for which the responsible politicians and the public only have little acceptance.

- Experienced (major) project managers are rare - in particular in public administration. Lacking qualification and expertise in project management results in methodical weaknesses of project planning and realization.

All these reasons are by the way also valid for projects beyond IT. However, in IT they seem to appear most frequently. 
Fortunately, some E-Government projects demonstrate that they can be realized successfully despite difficult environments in the public sector.

EU-wide, two pioneers in E-Government are Sweden and the Netherlands which enjoy their population's confidence and support in this field. The high E-Government usage ration of citizens (Sweden: 52\%, the Netherlands: 54\% (EU 27: 28\%)) and enterprises (Sweden: 78\%, the Netherlands: 85\% (EU 27: 68\%)) signalize how much the E-Government development is appreciated in these countries for the increase of efficiency and effectiveness in the public sector. The Scandinavians utilize the "e-Delegation", implemented in 2009, to ensure their plans for organizational and continuous development. The Dutch endeavors are embodied in the national "ICT agenda" whose realization is continuously pushed by the two organizations ICTU and GBO Overhaid.

Another example for a successful transformation process in the public sector is the introduction of the central telephone system "NYC 31" for public institutions in New York which was established by mayor Bloomberg in 2003. This project enabled all citizens to call public institutions at any time and quickly identify the right contact for their complaints and service requires - and that in over 170 languages. However, this project did not only bring along simplifications for the citizens but also for the decision makers within the city's administration. Based on the amount of available data "problem zones" within the town boundaries could quickly and exactly be identified through analytical methods. As a consequence, for example, all ambulances were equipped with GPS-devices which reduced the required time for giving first aid noticeably within 18 months.

Such successful projects exist also in Germany: recently, the Federal Employment Agency concluded a major project running over several years. Large parts of its IT landscape were replaced by a modern ERP solution based on standard software "in time and budget", implementing the functional benefit in the desired manner. To be successful with projects of this size (with costs in the three-digit million accounts) is not even the rule in private business.

These examples show that E-Government projects are absolutely capable of meeting the requirements of today's developments. But what can we learn from these positive examples and which role can Business and Information Systems Engineering (BISE) play in order to support future E-Government endeavors and lead to similar positive results?

- The integration and active participation of BISE in legislation is urgently recommended. In this way, potential consequences of the technical implementation can already be estimated and examined ex-ante. Thus, an E-Government law could determine the standards for the realization of IT-projects in the administration and hence create transparency for decision makers. Also establishing of a CIO minister could strengthen the position of IT when making decisions. Exemplarily, this has already been established in Germany since 2008 by the function of the representative of the Federal Government for information technology in the rank of permanent secretary for the federal administration. Moreover, Russia and Egypt have an own ministry for information and communication technology.

- As can be suspected from the mentioned negative examples above, governmental communication with interest groups - especially the citizens - plays an essential role. Only if BISE can successfully and transparently communicate the objectives behind such IT-projects, pointing out the benefit as well as the technical possibilities (attempts at a solution, tools, methods etc.), and addressing the issues of the public thoughts, can such projects be realized in future under consideration of the multiple and heterogeneous interest groups.

- This goes along with the support by the top-management. Successful IT-projects in private enterprises have shown that a clearly communicated mandate of leadership in the form of authorities for leading personalities in the IT-area as well as the unambiguous definition of the extent of the mandate within an organization can contribute to guarantee efficient decision processes. In the public sector it is essential to make sure that the political level of decision making supports such IT-projects in internal and external situations, especially in difficult periods. Analog to other IT-projects it is necessary to guarantee that there is a clear strategic orientation, a well-defined organizational environment and a system support with established and standardized methods and processes. 
- Since BISE is rooted in operational electronic data processing, another recommendation would be to transfer the findings from the private enterprise sector into the public sector. Exemplarily, the idea that customers are involved as an active part of companies through customer self services could also be transferred to governmental processes. This may lead to unsuspected opportunities, which could again result in more efficient processes within public institutions. The alignment with private enterprise would come along with the continuous observation of upcoming trends. Exemplarily, Web 2.0 technologies present new possibilities to contact citizens. In contrast to the corporate practice - which already applies these technologies for customer contact in a multitude of ways - they are comparatively seldom used in governmental institutions (United Nations 2010). In order to transfer the knowledge of private enterprise in a meaning way, we recommend to define convincing incentives and compensation for top-qualified IT-experts in order to make work within the administration more attractive and to guarantee the systematic building of IT-based capabilities.

- Finally, the lack of IT-experts in the public sector is even more striking than in private enterprise - also due to the clearly lower level of salaries and aggravated by the demographic development and the unfavorable age distribution in the public sector. Special attention should be paid to the acquisition of new and qualified IT-experts on the one hand, and to the further education and qualification of IT-experts on the other hand. Here, BISE must contribute by offering the corresponding education as well as by supplying research and development of the conceptual and methodical basics.

The ideas mentioned here are of course not able to offer a comprehensive and exhaustive attempt at a solution. However, they provide approaches for our scientific and practice-oriented discipline in order to embrace to the interface responsibility for conceptual and technical knowledge in the public sector.

\section{References}

Gartner (2010) Forecast: IT services 2008-2015, 2 Q11 Update

IDG NOA Sonderstudie (2010) E-Government- Monitor 2010 - Bürger und Staat. Beziehung gestört? http://www.initiatived21.de/wp-content/uploads/2010/07/IDG_NOA_Sonderstudie. pdf. Accessed 2011-07-28

Mertens P (2008) Fehlschläge bei IT-Großprojekten der Öffentlichen Verwaltung - Ein Beitrag zur Misserfolgsforschung in der Wirtschaftsinformatik. In: Multikonferenz Wirtschaftsinformatik 2008. GITO-Verlag, Berlin

United Nations (2010) E-Government survey 2010. Leveraging e-government at a time of financial and economic crisis. http://unpan1.un.org/intradoc/groups/public/documents/un/ unpan038851.pdf. Accessed 2011-08-05 